\title{
Strengthening Microscopy as a Strategy to Reduce Malaria in Jayapura City
}

\author{
Melda Suebu ${ }^{1 *}$, Ivon Ayomi ${ }^{1}$, Mardi Raharho ${ }^{1}$, Antonius Oktavian ${ }^{1}$, Octavianus \\ Karapa $^{1}$, Anton Wambraw ${ }^{2}$ \\ ${ }^{1 *}$ Centre for Papua Health Research and Development Papua, Indonesia \\ ${ }^{2}$ Public Health Faculty Universitas Cendrawasih, Indonesia \\ *Corresponding author, Email: msuebu@gmail.com
}

\begin{abstract}
Papua is still a malaria-endemic area, despite malaria prevention and treatment programs in the past and ongoing. To ensure quality microscopy services, a researcher wants to examine the microscopy capacity at the Public Health Services Center, to determine and the availability of laboratory facilities that support the work in the laboratory according to the Minister of Health Regulation. Objectivity; to evaluate the microscopy capacity in diagnosing malaria according to the National Guidelines of 2018 in 13 Public health service centers in Jayapura City. A mixed methods approach collecting quantitative data by a survey about the competence of laboratory staff from 13 participant and qualitative interview data about barriers and enablers to capacity building. $69 \%$ following training malaria and they all of not following refreshing training. $100 \%$ the number of microscopes in each malaria laboratory is one piece, the availability of water and light is available but it does not fully support the inspection activities in the laboratory. Almost all participants said they were not satisfied with the availability of laboratory facilities and the availability of laboratory reagents. To reduce the number of malaria cases, it is important to provide regular and repeated malaria technical training. It is also important to ensure the availability of quality laboratory equipment and reagents must also be of high quality. Baseline training and refresher training for malaria microscopists must be carried out regularly (ideally annually) and must be certified and the installation of laboratory reagent materials and materials must match the specifications and quality required by laboratory technicians.
\end{abstract}

Keywords: strengthening, microscopy, to reduce, malaria, Jayapura

\section{INTRODUCTION}

Malaria is one of the major public health problems worldwide. There for 216 million cases of malaria, and 445.000 death in worldwide in 2016. There were an estimated 219 million cases and 435 000. Despite malaria control program has distributed insecticide treated nets (ITN), sprayed the inside walls of homes with insecticides (IRS), implemented an Integrated Vector Management (IVM) approach to vector control. In 2017. There were an estimated 219 million cases and 435000 related deaths.

In Indonesia, cases of death due to malaria are around 38,000 cases each year 4. Most cases of malaria in Indonesia occur in eastern Indonesia (80\% of national cases) [5]. During the period 2014-2017. Jayapura city recorded an Annual Parasite Index [API $\}>5$ per 1000 population defining it as a highly endemic area of malaria6. Malaria case numbers increased every year, in Papua, especially in Jayapura City, a malaria elimination strategy needs to be implemented. Based on the decision of the Minister of Health of the Republic of Indonesia in 2009 to eliminate Malaria in Indonesia, it was stated that the province of Papua should eliminate Malaria by 2030. Based on the national guidelines this includes the activities of standardized monitoring of clinical cases and confirmatory diagnosis including microscopic examination.

To ensure quality microscopic examination the ability of laboratory staff and the availability of laboratory facilities is critical. However up to now, despite the elimination of malaria remaining a priority, malaria in Jayapura City is still a health problem. This research aims to evaluate the microscopy capacity in diagnosing malaria according to the National Guidelines of 2018 in 12 Public health service centers. 
Cross-sectional survey In total, 13 Health Walker (9 female [69\%]), and 4 Male (31\%) from 13 PHSC completed questionnaires. The median age of participants was 35 years (range 30-45 years). The majority of participants $(85 \%)$ were between 30 and 40 years with $100 \%$ currently married. Participants. The majority of participants ( $69 \%$ ) The length of working about 10-20 years.

Quantitative data were generated in two major areas: (1) Characteristic of Responden (2) Competence of Health Walker (3) Laboratory Facility (Table 1, 2 and 3) the majority of participants $(69 \%)$ following traning malaria, but only half $(31 \%)$ Not following traning malaria. the all off participant $(100 \%)$ not following refreshing training malaria. The availability of laboratory facilities in quantity available, but in terms of quality laboratory facilities become a major problem at work.

For the open-ended question, asked on several points, namely: 1) Competence of malaria training, as evidenced by the ownership of training certificates. 2) Satisfaction of using current laboratory facilities. 3) Work procedures for malaria parasite inspection according to Standart Operational Procedure (SOP). The first theme "Need for refresher training" (training is given to subordinates who like or proximity factors" related to Health walker (female) in the following response: "here, not all of us can participate in the training, we who work day to day check for malaria, who will take part in the training is the person in charge of the program, for us this is not true, because the person responsible for the program does not conduct a malaria check.During training we rarely get training certificates. We ask the committee but the answer is not certified. Ongoing training is rarely done. For example, if we take the malaria level 1 training, there is never another level 2 training, even if there are others who follow it later, it will never be fun.

"We need training here to refresher whether we have this analysis, right or no" (Female, PHSC )

"Just suggest, if possible for training should be available every year" (Female, PHSC )

The second theme "Availability of reageng"

"we use giemsa to buy it ourselves from BPJS. Stock giemsa from the pharmaceutical warehouse is giemsa mixture. Try to imagine, giemsa concoction, Chinese microscope, we sure, we will destroyed in the lab" (Female, PHSC)

"The third theme "Quality of microscope" The main facility that we use for malaria testing is a microscope. How can we read the results well, if the image has a bad staining, the microscope we need is the Olympus brand, but what comes for us use is a not we needed microscope. 
"Giemsa made our own, microscopes ugly, we have been destroyed in this lab" (Femele, PHSC).

" our microsope we receive all made in China, we don't use them. It's better to buy just one Olympus, we are happy we don't like made in china. Ugly. (Female, PHSC)

Table 2. Facility Laboratory

\begin{tabular}{lcl}
\hline Facility Laboratory & $\begin{array}{c}\text { Number } \\
(\mathbf{N}=\mathbf{1 3})\end{array}$ & Percentage \\
\hline Microscope & 13 & $100 \%$ \\
\hline Lighting & 13 & $100 \%$ \\
\hline Standing & 13 & $100 \%$ \\
\hline Water availability & 13 & $100 \%$ \\
\hline Storeage cabinet & 0 & $100 \%$ \\
\hline
\end{tabular}

$100 \%$ of facilities reported having a microscope, adequate lighting, staining and available water. None had a storage cabinet as recommended for their microscope;

The fourth theme "work use guidelines" 13 Puskesmas work using guidelines from WHO and the Ministry of Health. But not all stages are carried out. "We only take thick blood, not taking thin blood, because it is not needed by doctors.cross checker, never check the results of our inspection. A part from this response, some people in charge of the malaria program said that "as the person in charge of the laboratory must understand the work in the laboratory, so it is not always necessary for the laboratory assistant to take part in the training, because the training material is usually shared again with laboratory friends, all laboratory assistants are in here anyone can check for malaria, it doesn't have to be a malaria officer, TB officers can also check malaria depending on the situation and conditions at work.

Another reason given by the person in charge of the laboratory is that malaria training is limited in membership, "so we expect the development of malaria technicians to improve their competence by self-study, lots of malaria books, modules that can be used. And for the question of inappropriate reagent materials and the procurement of inappropriate microscopes, it is very unfortunate, because the instruments held are not in accordance with our proposal". Malaria training carried out by the health department, not all laboratory analysts attended the training. As many as 9 people $(69 \%)$ who participated in the training, the remaining 4 people $(31 \%)$ said that they did not attend training because they did not receive any information. Likewise, with ongoing training, all labatorium officers stated that no sustainable malaria training had been conducted.

Overall $100 \%$ of Public Health Service Centre have microscopes but $100 \%$ of the microscopes do not have storage cabinets. The microscope will be damaged quickly, due to fungus due to improper storage temperature. For microscopes that have low quality at low prices, the results of poor illumination of the dyes provided with poor quality make it difficult for malaria technicians to read malaria slides

The availability of laboratory equipment is an operational requirement that supports the results of the examination. Therefore, the quality of laboratory equipment and materials must be an important concern to achieve all that, good communication is needed internally. The main objective of this study is to assess the competence of malaria laboratory personnel, availability of laboratory facilities and work using guidelines. One of the strages to realize the elimination of Malaria in Papua Province, is the role of the regional government as sounded in the policy implementation regulations that have been established that one of the competency criteria for laboratory personnel is to have participated in training according to the National standard for the last 3 (three) years. Tujuan dari pelatihan adalah untuk meningkatkan pengetahuan dan ketrampian petugas laboratorium dalam program pengendalian malaria.

It is feared that data on the high number of malaria cases is actually not malaria positive, but false positives, due to mistakes in reading slides, therefore the strategy needed to panticipate this is: Malaria technicians are required without exception to take malaria training and continuous training and have certified Training given to staff has a positive effect on improving the quality of data, compared to staff who have never attended training, training attended by staff can make staff skilled and skilled in their work. The more training provided to staff, the better the quality of data presentation. The more training provided the better the work of the staff participating in the training.

Supporting facilities for malaria case finding consist of adequate rapid diagnostic testing (RDT), 1-2 microscopes at each community health center, adequate reagents, adequate sliding glass, and adequate artemisinin-based combination therapy (ACT). To support good performance, good support facilities are needed, good supervision systems, tools and reagent materials meet quality standards, a good training refresher program is also required which is provided according to national standards. Even now, malaria treatment should only be given after laboratory confirmation. Microscopy of a thick and thin blood film stained with Giemsa remains the gold standard for diagnosis of malaria infection. While our results show that laboratory workers only take thick blood preparations, as quoted below,

"Here we are only taking thick blood smears, thin blood smears are not done, because there is no need for a doctor" ( Femele, PHSC)

Very different from the condition of the examination of malaria parasites in 13 health centers in Jayapura City which only carry out the diagnosis of malaria blood sampling thick blood smears. The availability of adequate laboratory facilities should be supported by laboratory 
http://www.who.int/malaria/media/world_malari a_report_2013/en/.

malaria microscopy requires:. A good training system is applied based on competencies relevant to clinical settings. Regular retraining and competency assessment/assessment, supported by a validated set of reference

\section{CONCLUSION}

To reduce the number of malaria cases not only provide malaria technical training, but the availability of quality laboratory equipment and reagents must also be of high quality and build a good communication system.

\section{ACKNOWLEDGMENT}

1. The research team for the implementation of the Papua Health Research and Development Center; Ivon Ayomi, Mardi Raharjo, Octovianus Karapa, Antonius Oktavian, Anton Wambraw.

2. Health Walker in 13 Publich Health Service Center, Jayapura City, was support this recearch like as respondent.

3. Health Departement of Papua Province, who gave permission to conduct research.

4. Head of Papua Health Research and Development Center, who gave permission to conduct research.

5. Dr Karen CarlisleBSc. (Hons.), PhD Senior Research Fellow College of Medicine and Dentistry. James Cook University. like as Mentor.

6. Professor Sarah Larkins Associate Dean, Research College of Medicine and Dentistry Co-Director, Anton Breinl Centre for Health Systems Strengthening James Cook University Douglas QLD 4811. like as Mentor.

7. Professor Maxine Whittaker, Dean, College of Public Health, Medical and Veterinary Sciences CoDirector WHO Collaborating Centre for Vector Borne and Neglected Tropical Diseases. Division of Tropical Health and Medicine James Cook University, Townsville, Queensland 4811 AUSTRALIA.like as Mentor

\section{REFERENCES}

[1] World Health Organization (WHO).World malaria report [Factsheet on the World Malaria Report Geneva: World Health Organization;2013 accesse 01 march 2018). Available

from:
[2] World Health Organization (WHO) Global Respond To Malaria 29 November 2017 Genevahttp://www.who.int/mediacentre/news/re leases/2017/malaria-report-response/en/ Date accessed: 01 March 2018.

[3] Karolus ngambut, Octofianus Sila. 2013: envirotment and public behavior Faktor about Malaria in east kupang Subdistrict Kupang. National Health Journal.Vol.7. No.6 pages 272.

[4] Dinas Kesehatan Profinsi Papua. Papua Health Profile 2014 Jayapura.

[5] InfoDATIN. 2014. Situasi Malaria Di Indonesia Pusat Data dan Informasi Kementerian KesehatanRI.Availablefrom:http://www.depkes. go.id/resources/download/pusdatin/infodatin/inf odatin-malaria.pdfTodays date 01 March 2018.

[6] Book management of malaria cases. Dirjen P2PL. Ministry of Health Indonesia 2012 which city published in ?Jakarta.

[7] Decree of the minister of health of the republic of indonesia number 293 / menkes / sk / iv / 2009 about elimination of malaria in indonesia. Website Need to give that web address and the date you accessed it

[8] http://www.who.int/malaria/areas/test_treat_trac k/en/ Accessed 3 March 2018.

[9] Malaria Journal 2016 Consolidating tactical planning and implementation frameworks for integrated vector management in Uganda. https://malariajournal.biomedcentral.com/article s/10.1186/s12936-016-1269-7.Today date 03 March 2018.

[10] Nasaruddin Fadillah. 2008. Pengaruh Pendidikan, Pelatihan, dan Pengalaman Kerja Terhadap Kualitas Penyajian Informasi Akuntansi pada PT. Bank Negara Indonesia Tbk. (Studi pada Kantor Cabang BNI di Provinsi Sulawesi Selatan). Jurnal Ichsan Gorontalo, Vol. 3, No. 1 